\title{
Quem são e o que fazem as empresas brasileiras? Análise das declarações de missão
}

\author{
ANDRÉ REHBEIN SATHLER ${ }^{1}$ \\ ROBERTO CAMPOS DA ROCHA MIRANDA ${ }^{2}$ \\ ${ }^{1}$ Centro Universitário iesb / Escola de Negócios, Brasília - DF, Brasil \\ ${ }^{2}$ Centro de Formação, Treinamento e Aperfeiçoamento da Câmara dos Deputados, Brasília - DF, Brasil
}

\section{Resumo}

O objetivo deste artigo é traçar um perfil identitário das maiores empresas brasileiras, a partir da análise de suas declarações de missão (DM). A estratégia de pesquisa foi qualitativa, com uso de técnicas de análise de discurso. O referencial teórico central provém do campo de gestão estratégica. Os resultados indicam que a maioria das empresas ostenta uma DM em seus sites na internet. Estas refletem uma adequação em termos dos componentes previstos para uma boa DM - 71,7\% apresentam os elementos "metas", "políticas/valores" e "escopos competitivos", previstos na literatura. Predomina o foco externo (clientes). Os resultados demonstram que a técnica de elaboração e uso de DM são bem difundidas e aceitas no Brasil, havendo espaço, contudo, para aperfeiçoamentos em termos do conteúdo delas. O artigo identifica lacunas que sugerem futuros estudos, como a análise comparada de desempenho entre empresas com diferentes perfis identitários, explicitados em suas DM.

Palavras-chave: Gestão estratégica. Declaração de missão. Foco no cliente. Análise de discurso.

\section{Who are the Brazilian companies and what do they do? Analyses of mission statements}

\section{Abstract}

The research aims to delineate an identity profile of the 500 biggest Brazilian companies based on their mission statements. It is a qualitative study, using discourse and content analyses, and the theoretical framework is grounded in the field of strategic management. The study identified that the majority of Brazilian companies include their mission statement on their website. The analysis shows that $71,7 \%$ of the statements have the components recommended by the literature for a good mission statement - "goals," "policies/values," and "competitive arena" - and revels the predominance of an external focus (customers). The results show that the technique of elaborating and using mission statements is widespread in Brazil, but there is room for improvement in terms of contents. The article identifies new possibilities for research, such as a comparative analysis of performance among companies with different identity profiles, regarding their mission statements.

Keywords: Strategic management. Mission statements. Focus on customers. Management discourse. Content analysis.

\section{¿Quiénes son y qué hacen las empresas brasileñas? Análisis de las declaraciones de misión}

\section{Resumen}

El objetivo de la investigación es establecer un perfil de identidad de las compañías brasileñas más grandes, basándose en el análisis de sus declaraciones de misión. La estrategia de investigación es cualitativa, con el uso de técnicas de análisis del discurso. El marco teórico central proviene del campo de gestión estratégica. Los resultados indican que la mayoría de las empresas ostenta una declaración de misión en sus sitios web. Estas empresas reflejan una adecuación en términos de los componentes pronosticados para una buena declaración de misión: el $71.7 \%$ presenta los elementos "objetivos", "políticas/valores" y "ámbitos competitivos", previstos en la literatura. Predomina el enfoque externo (clientes). Los resultados demuestran que la técnica de elaboración y uso de las declaraciones de misión está bien difundida y aceptada en Brasil, pero hay espacio para perfeccionamientos en términos de su contenido. El artículo identifica lagunas que pueden dar lugar a estudios futuros, como el análisis comparativo del desempeño entre compañías con diferentes perfiles de identidad, explicitados en sus declaraciones de misión.

Palabras clave: Gestión estratégica. Declaraciones de misión. Foco en el cliente. Discurso de gestión Análisis del contenido. 


\section{INTRODUÇÃO}

O objetivo deste artigo é traçar um perfil identitário das maiores empresas brasileiras, a partir da análise de suas declarações de missão (DM). O tema é abordado a partir do campo da gestão estratégica, embora também faça parte de estudos de comportamento organizacional, uma vez que as DM são manifestações discursivas, autodeclarativas, quanto à identidade das organizações, com reflexos, desejados ou esperados, sobre seus fazeres. De fato, segundo Drucker (1973), uma DM, ao procurar responder "qual é o nosso negócio", relembra à empresa suas origens.

As DM já foram estudadas quanto ao processo de sua formulação, aos seus componentes ideais e ao(s) papel e efeitos sobre o desempenho (BART, BONTIS e TAGGAR, 2001; KOTLER, 2000; BART, 2000; ABRAHAMS, 1995; IRELAND e HITT, 1992; COLLINS e PORRAS, 1991; FALSEY, 1989; DAVID, 1989; PEARCE, 1982; DRUCKER, 1973). Esses estudos, entretanto, abordaram DM em empresas estrangeiras. Não foram localizados estudos de recorte semelhante com vistas à DM em português ou de empresas brasileiras.

Portanto, esta pesquisa visa a contribuir para o preenchimento de algumas lacunas. A primeira se refere à possibilidade de descrever o estado da arte da questão no contexto das 500 maiores empresas brasileiras - quais apresentam ou não uma DM em seus sites na internet. De forma indireta, esse levantamento também funciona como indicador da absorção da literatura sobre estratégia competitiva em termos práticos pelo conjunto das maiores empresas nacionais. A segunda lacuna se refere ao aspecto formal das DM em língua portuguesa - como são redigidas, principais termos utilizados, vieses competitivos apresentados. Por fim, uma terceira lacuna é a falta de análise de DM em português no que tange à presença de certos componentes considerados básicos pela literatura sobre o assunto, como será apresentado.

Optou-se pelo modelo de Kotler (2000) como referência para a identificação dos componentes básicos necessários a uma boa DM. Com base em análise de discurso, também se constroem categorias dicotômicas para classificação de cada DM, que ensejaram a construção de um modelo bidimensional, que pode servir de base para futuras pesquisas.

Trata-se de tarefa ampla e ensejadora de várias pesquisas interdependentes. A opção inicial, portanto, foi pela abordagem exploratória, descritiva e classificatória, com vistas a delimitar o campo para pesquisas futuras. As metas deste artigo são apresentar o estado da arte no contexto das 500 maiores empresas brasileiras, submetendo as DM encontradas a um procedimento taxonômico, disjuntivo e exaustivo. A estratégia de pesquisa é qualitativa, com uso de técnicas de análise de conteúdo e análise de discurso.

\section{REFERENCIAL TEÓRICO}

Esta pesquisa dialoga com conceitos de estratégia como design, como proposto por Mintzberg, Ahlstrand e Lampel (2000), e também com a literatura sobre estratégia de uma forma geral, ressaltando-se os autores Zaccarelli (2000), Day e Reibstein (1999), Porter (1986, 1989, 1999), Zaccarelli e Fischmann (1994), Ansoff e McDonnell (1993). Segundo Mintzberg, Ahlstrand e Lampel (2000), entender a estratégia como design é afirmar sua formulação como um processo de concepção. Ainda segundo esses autores, tal visão propõe um modelo de formulação de estratégia que busca atingir uma adequação entre as capacidades internas das empresas e suas possibilidades externas.

O passo inicial da formulação da estratégia, para a escola de design, é a analítica das perspectivas externa (ameaças e oportunidades) e interna (forças e fraquezas), da qual derivam fatores-chave de sucesso (diante das perspectivas externas) e competências distintivas (diante das perspectivas internas). A partir dessa analítica, produz-se a criação da estratégia. Graças ao seu uso por diversas consultorias, sua intuitividade e facilidade de aplicação, esse tipo de análise se tornou recorrente no ambiente empresarial e o acrônimo em inglês da técnica (strengths, weaknesses, opportunities, and competitive threats SWOT) se tornou amplamente disseminado. Por essa razão, mesmo processos diferenciados de formulação estratégica, que utilizam outras metodologias, passaram a incorporar análises do tipo SWOT em seus momentos iniciais.

Na prática, as DM passaram a ser concebidas no momento em que se conclui a analítica das perspectivas externa e interna, constituindo um processo deliberado de pensamento consciente, com a ação fluindo da razão, em consonância com o proposto por Mintzberg, Ahlstrand e Lampel (2000). As DM devem ser simples e resultar de um processo individualizado, uma vez que 
vão refletir a situação específica da empresa. Ainda segundo os autores citados, esse processo deve "acima de tudo, ser um ato criativo, para construir sobre a competência distintiva" (MINTZBERG, AHLSTRAND e LAMPEL, 2000, p. 33).

Com a formulação da DM se torna possível a derivação da estratégia a ser seguida pela empresa. Portanto, o processo é deliberado, não emergente. A DM surge como um conceito global do negócio, usualmente oriunda dos escalões superiores da empresa ou formulada com a participação deles. Assume a característica que Mintzberg, Ahlstrand e Lampel (2000) denominam perspectiva.

As origens da escola de design remontam às décadas de 1950 e 60, com os trabalhos seminais de Selznick (1957) e Chandler (1962). Ganhou repercussão a partir de sua adoção pela Harvard Business School, a partir de 1965, que incluiu a questão em seu livro-texto básico, como lembram Mintzberg, Ahlstrand e Lampel (2000, p. 28). A obra de Peter Drucker, do início da década de 1970, trouxe outra dimensão, ao recuperar a noção de que as empresas deviam se repensar e responder à questão "qual é o nosso negócio?". Para Drucker (1973), essa pergunta era idêntica à questão "qual é a nossa missão". A DM seria, portanto, a expressão da raison d'être da empresa, aquilo que a distinguiria de outras empresas similares. Concordam com essa perspectiva Campbell e Yeung (1991); Pearce e David (1987), Pearce (1982). Apesar de não mencionar esse fato, a afirmação de Drucker (1973) sinaliza que um propósito maior não se inventa, já existe. Na verdade, Drucker (1973) começa sua digressão sobre o assunto afirmando ser necessário recuperar o sentido que às vezes fica esquecido. Talvez por essa razão, as DM formuladas às pressas e exclusivamente com o apoio de consultorias, sem genuína participação dos colaboradores, acabem por ser platitudes, sem efeito prático. $O$ risco dessa possibilidade se ampliou quando as DM se tornaram uma febre no meio empresarial, na década de 1980 (WILLIAMS, 2008).

A DM deve trazer uma clareza de propósito que se agrega ao patrimônio intangível da organização, ao criar entre todos os colaboradores um elo emocional, tornando possível a coexistência mais harmoniosa entre os interesses da empresa e os de seus empregados. Drucker (2002, p. 40) ressalta esse papel de produzir coesão das DM:

[...] a organização deve ser determinada, ou seus membros ficarão confusos. Eles seguirão sua própria especialidade em vez de se dedicar à tarefa comum. Cada um deles definirá "resultados" em termos de sua própria especialidade e imporá seus valores à organização. Somente uma missão focalizada e comum irá manter a organização unida e permitirá que ela produza.

A DM é componente, portanto, da ideologia das empresas e de suas culturas corporativas, constituindo-se como instrumento de uso externo e interno, reforçadora e reforçada por práticas concretas. Assim, as DM favorecem a identificação com a organização, a interiorização de seus objetivos e de seus valores. Tal identificação com a missão pode cumprir o papel de substituir a adesão pessoal à chefia, prevalente nos ambientes da administração clássica.

Outro impulso para as DM veio de um artigo seminal de Theodore Levitt (2017) intitulado "Miopia do marketing" (cuja versão original foi publicada em 1960). O ponto central do artigo era que as empresas deveriam, no processo de conceber suas DM, ter como referência uma ampla orientação da indústria, ou a quais necessidades genéricas subjacentes ela atendia. Na opinião de Levitt (2017, p. 149), por exemplo, empresas ferroviárias deveriam ver-se como inseridas no negócio de transportes:

[...] as ferrovias estão com problemas não porque essas funções tenham sido preenchidas por outros meios (carros, caminhões, aviões e até telefones), mas porque as próprias ferrovias permitiram que outros se apropriassem de seus clientes. Elas se sentiam pertencentes ao negócio de ferrovias, não ao de transportes.

Para Levitt (2017), a definição restrita de um setor ou produto resultava em um envelhecimento prematuro. A indústria deveria pensar sobre o cliente e suas necessidades.

Apesar de prover um insight interessante e mobilizador para as empresas, a proposta de Levitt (2017) resultou em alguns casos de DM extremamente ambiciosas, ambíguas ou nonsense, o que reduziu sua utilidade. Vários autores criticaram a posição de Levitt (2017). Kotler e Singh (1981) afirmaram que, ao redefinir a estratégia em termos de perspectiva, ao invés de posicionamento, Levitt (2017), na verdade, tinha reduzido sua amplitude, com a capacidade interna das empresas perdendo valor e as oportunidades de mercado sendo ressaltadas. Baughman (1974) considerou que as DM passaram a ampliar segmentos de mercado estreitos além do que seria prudente. Mintzberg, Ahlstrand e Lampel (2000) consideraram a visão equivocada, uma miopia em si - a miopia da miopia do marketing. 
Uma DM “diz duas coisas sobre uma empresa: quem ela é e o que ela faz" (FALSEY, 1989, p. 3, tradução nossa). Essa definição encontra similares em Bart, Bontis e Taggar (2001), Bart (2000), Abrahams (1995), Ireland e Hitt (1992), Collins e Porras (1991), David (1989), Pearce (1982) e no já mencionado trabalho de Drucker (1973). Segundo Kotler (2000, p. 87) “uma declaração de missão bem formulada dá aos funcionários um senso compartilhado de propósito, direção e oportunidade". Os estudos internacionais mencionados convergiram para a apresentação de 9 componentes que deveriam estar presentes em DM informações sobre: os clientes; os funcionários; os produtos ou serviços; os mercados; a tecnologia; o autoconceito; a imagem pública desejada; a filosofia; e as estratégias para o crescimento e a sobrevivência. Kotler (2000), contudo, simplifica essa questão apontando 3 características principais de uma boa DM: metas; principais políticas; e valores e principais escopos competitivos dentro dos quais a empresa operará (KOTLER, 2000).

De acordo com a literatura, as DM devem cumprir as seguintes finalidades: afirmar a liderança (KLEMM, SANDERSON e LUFFMAN, 1991); comunicar os objetivos e as metas da empresa aos seus colaboradores (BART, 1998; IRELAND e HITT, 1992); funcionar como um instrumento de relações públicas (DAVID, 2007; BART, 1998; FALSEY, 1989); fundamentar racionalmente a alocação de recursos (POWERS, 2012; DAVID, 2007; BART, 1998); servir como diretriz para as decisões estratégicas (DROHAN, 1999); ser fator motivacional e inspirador (SASHITTAL e TANKERSLEY, 1997, COLLINS e PORRAS, 1991; IRELAND e HITT, 1992).

King e Cleland (1979) recomendam que as empresas desenvolvam cuidadosamente DM escritas, com os seguintes objetivos: assegurar que todos os colaboradores compreendam a razão de existência da empresa; ser uma diretriz para decisões de priorização alocação de recursos; funcionar como um sentido comum de propósito para todos os departamentos, colaboradores, atividades e segmentos dentro da empresa. Consequentemente, se uma DM pode cumprir tantos papeis, ainda que não todos ao mesmo tempo, o assunto ganha relevância de pesquisa, como comprovado pela ampla literatura internacional sobre o assunto.

Outro papel importante das DM é promover uma ligação entre estratégia e cultura. As estratégias oferecem uma lógica formal para que os colaboradores compreendam as metas da empresa e possam orientar-se em torno delas. Já a cultura expressa essas metas por meio de valores e crenças compartilhadas. É a cultura que molda a ordem social tácita nas organizações, definindo atitudes e comportamentos perenes. Para que a cultura seja forte, os valores são importantes e as DM contribuem para a geração de culturas aspiracionais que vão sinalizar aos colaboradores quais são os princípios de alto nível que guiam as iniciativas empresariais.

Para que possam cumprir esses papeis, as DM devem ser apreendidas pelos colaboradores, que precisam impulsionar o processo, permitindo que o propósito passe a permear a cultura e moldar o comportamento, mesmo quando os gestores não estão presentes para supervisionar as pessoas. Dessa forma, os valores expressos pelas DM serão efetivamente os critérios que os colaboradores utilizarão para tomar as decisões relevantes. Ressalte-se que essa é a premissa idealizada em relação à técnica de redação e ao uso de uma DM, constituindo quase que uma "utopia" da gestão estratégica. As DM auxiliam de modo que as empresas sejam vistas como coletividades às quais os colaboradores pertencem, ao invés de ser vistas apenas como um local de trabalho no qual se reúnem indivíduos isolados. Com isso, as DM fazem com que os trabalhadores tenham uma chance de alcançar "auto-respeito, através de servir dentro do sistema, mesmo que possa haver muitos aspectos dentro do sistema que acham aversivos" (MORGAN, 1996, p. 121). Em outros termos, Morgan (1996) afirma que as DM romanceiam a vida organizacional.

Nos termos dos institucionalistas Berger e Luckmann (1985), as DM são elementos da construção social da realidade dentro das organizações. Nestas, segundo os autores, "a socialização secundária exige a aquisição de vocabulários específicos de funções, o que significa em primeiro lugar a interiorização de campos semânticos que estruturam interpretações e condutas de rotina em uma área institucional" (BERGER e LUCKMANN, 1985, p. 185). Nesses termos, as DM são "campos semânticos" a ser "interiorizados". A atribuição de significados aos acontecimentos no ambiente corporativo é um processo social complexo, no qual as pessoas dão sentido aos fatos de uma forma ativa e interagem com outros, negociando os conteúdos simbólicos envolvidos. O processo de construção de significado é um encontro criativo entre uma complexa e estruturada forma simbólica, de um lado, e as pessoas, de outro, que trazem seus próprios recursos e pressuposições para as apoiar na atividade de interpretação da realidade.

De caráter discursivo, as DM nos lembram que "todo discurso gera poder" (COELHO NETTO, 2003, p. 101), o que pode ser descrito como sendo os efeitos do discurso no âmbito de determinada trama de relações sociais (organizações). São "efeitos na trama e efeitos que geram a trama" (COELHO NETTO, 2003, p. 101). Essa tessitura de signos constrói edifícios de 
representação simbólica (BERGER e LUCKMANN, 1985) que pairam sobre a realidade da vida cotidiana. Berger e Luckmann (1985) também chamam a atenção para o caráter discursivo, refletindo que somente a linguagem tem a capacidade de construir símbolos altamente abstraídos da experiência diária, mas também de "fazer retornar' estes símbolos, apresentando-os como elementos objetivamente reais na vida cotidiana" (BERGER e LUCKMANN, 1985, p. 61). Ou seja, exatamente o que se espera das DM, que construam campos semânticos ou zonas de significação linguisticamente circunscritas, fornecendo sentidos integradores que abranjam a empresa como um todo, oferecendo um contexto para compreensão da experiência e superação do conhecimento social fragmentado do indivíduo. Essa dimensão nos faz pensar que, ainda que sejam formuladas como platitudes, as DM podem contribuir para a empresa, pois representam um espírito geral, um ideal, que por si só contribui para o moral dos colaboradores.

Portanto, as DM como expressões de uma coletividade permanecem em equilíbrio dialético entre passado e futuro, movimento e repouso, desequilíbrio e reequilíbrio, mudança e preservação da forma tradicional. Elas vigoram nas consciências dos colaboradores e é dessa forma que engendram comportamentos, desde que exista a convicção em sua legitimidade. Esta será maior ou menor a depender de sua construção participativa ou de sua imposição pela alta administração.

\section{METODOLOGIA}

Esta pesquisa, de natureza qualitativa, combinou procedimentos da análise de conteúdo e da análise de discurso, cujas especificações são apresentadas adiante. Estudos similares internacionais utilizam ambas as abordagens - análise de conteúdo (WILLIAMS, 2008) e análise de discurso (M. E. DAVID, F. R. DAVID e F. R. DAVID, 2014).

A análise de conteúdo foi utilizada como primeira abordagem aos textos, servindo tanto para uma descrição do corpus, com alguns elementos quantitativos, quanto para a construção das categorias de análise. Bardin (2011) e Krippendorff (1990) tratam a análise de conteúdo $(\mathrm{AC})$ como um conjunto de técnicas de investigação destinadas a formular inferências reproduzíveis e válidas. Utilizamos duas técnicas de AC. A primeira foi a análise descritiva do corpus, que consiste em sua apreensão em termos quantitativos. A segunda foi a análise categorial, que consiste na classificação dos temas a partir de categorias analíticas, uma espécie de mapeamento taxionômico do corpus, com o objetivo de estabelecer a "carga avaliativa das unidades de significação tomadas em conta" (BARDIN, 2011, p. 203-204). Na construção das categorias e na classificação das respectivas DM recorremos, ainda, à análise de discurso, em consonância com a teoria da estratégia como design (estratégias formuladas explícita e discursivamente).

Portanto, as categorias foram construídas ao longo da pesquisa, a partir de aproximações sucessivas ao corpus, abrangendo pré-análise, análise exploratória e tratamento interpretativo inicial (BARDIN, 2011). O tratamento descritivo e a identificação das categorias foram auxiliados pela utilização do software Text Analyzer. O procedimento foi taxonômico (classificações multidimensionais), disjuntivo (classificações por critérios dicotômicos mutuamente exclusivos) e exaustivo (todas as DM foram classificadas).

Os autores recorreram à Edição Especial da Exame, Melhores e Maiores: as 1000 maiores empresas do Brasil de 2017 para identificar as 500 maiores empresas do país, que constituiu o universo de pesquisa. Estudos similares no exterior recorreram à lista da Fortune 1000 (M. E. DAVID, F. R. DAVID e F. R. DAVID, 2014; WILLIAMS, 2008) e à Forbes Best Small Business (C. H. AMATO e L. H. AMATO, 2002). A partir da relação, os autores consultaram os sites das empresas, buscando informações sobre a DM na página inicial e em até 2 subpáginas - no máximo 2 cliques a partir da página inicial, utilizando os sistemas de pesquisa dos próprios sites, procedimento também utilizado por M. E. David, F. R. David e F. R. David (2014). Caso não encontrassem uma DM nesse nível, consideraram como não existente. Também não foram consideradas DM em língua estrangeira, dada a metodologia escolhida (análise de discurso em língua portuguesa).

No nível do tratamento descritivo, aplicou-se uma classificação relacionada ao referencial apontado por Kotler (2000, p. 88) quanto aos elementos indispensáveis a uma DM (metas, políticas/valores, escopos competitivos). Optou-se por essa aplicação em virtude da decisão de trabalhar com o universo das 500 maiores empresas (estudo internacional que adotou os 9 componentes usualmente apontados pela literatura trabalhou com uma amostra muito inferior, de 20 DM). A opção de trabalhar com as 500 maiores também se justifica pelo fato de não terem sido identificados estudos do gênero na literatura nacional, sendo positiva a apresentação de um estudo com caráter exploratório. 
No tocante à construção das categorias e sua aplicação às DM, os autores o fizeram intersubjetivamente, classificando em um primeiro momento de forma individual e em um segundo momento confrontando as escolhas e chegando a um acordo quanto à classificação a ser mantida nos casos em que houve divergência. Procedimento semelhante foi adotado por M. E. David, F. R. David e F. R. David (2014).

\section{RESULTADOS}

\section{Tratamento descritivo}

Foram encontradas 297 DM, o que representa 59,4\% do total. Esse é o corpus. As DM foram compostas por 7.366 palavras, o que significa uma quantidade média de 24,8 palavras por DM. No corpus, 261 DM são iniciadas com verbos (87,8\%), percentual explicável pela natureza específica das DM - expressar o que as empresas fazem. Excluídas as preposições e os artigos, as palavras com maior frequência (acima de 0,5\%) são listadas na Tabela 1.

Tabela 1

Palavras mais frequentes

\begin{tabular}{c|c|c}
\hline Palavra & Ocorrências & Frequência (\%) \\
\hline clientes & 86 & 1,16 \\
\hline qualidade & 78 & 1,05 \\
\hline serviços & 75 & 1,01 \\
\hline nossos & 64 & 0,86 \\
\hline sustentável & 64 & 0,86 \\
\hline produtos & 61 & 0,82 \\
\hline valor & 57 & 0,77 \\
\hline desenvolvimento & 54 & 0,73 \\
\hline meio & 51 & 0,69 \\
\hline pessoas & 50 & 0,67 \\
\hline soluções & 48 & 0,65 \\
\hline excelência & 45 & 0,61 \\
\hline vida & 44 & 0,59 \\
\hline forma & 43 & 0,58 \\
\hline energia & 42 & 0,57 \\
\hline saúde & 41 & 0,55 \\
\hline acionistas & 41 & 0,55 \\
\hline colaboradores & 41 & 0,55 \\
\hline sociedade & 38 & 0,51 \\
\hline
\end{tabular}

Fonte: Elaborada pelos autores. 
A aplicação do referencial de Kotler (2000, p. 88) quanto aos elementos indispensáveis a uma DM (metas, políticas/valores, escopos competitivos) é contemplada na Tabela 2.

Tabela 2

Composição das declarações quanto ao referencial de Kotler

\begin{tabular}{l|c|c}
\multicolumn{1}{c|}{ Elementos } & Quantidade & $\%$ \\
\hline Metas, políticas/valores, escopos competitivos & 213 & 71,7 \\
\hline Metas, políticas/valores & 35 & 11,8 \\
\hline Metas, escopos competitivos & 34 & 11,4 \\
\hline Metas & 13 & 4,5 \\
\hline Políticas/valores, escopos competitivos & 0 & 0 \\
\hline Políticas/valores & 1 & 0,3 \\
\hline Escopos competitivos & 0 & 0 \\
\hline Nenhum dos elementos presentes & 1 & 0,3 \\
\hline
\end{tabular}

Fonte: Elaborada pelos autores.

\section{Categorização}

No tocante às categorias, foram construídas ao longo da pesquisa, como já argumentado. São categorias dicotômicas, o que significa que, em cada par, a escolha de um implica a não escolha do outro. São os pares: concreta/abstrata; descritiva/ aspiracional; externa/interna; defensiva/agressiva. A Tabela 3 apresenta as categorias, sua definição em termos de marcadores semânticos e a quantidade de ocorrências.

Tabela 3

Categorias - marcadores semânticos

\begin{tabular}{c|l|c}
\hline Categoria & \multicolumn{1}{|c}{ Marcador semântico } & Ocorrências* \\
\hline Concreta & $\begin{array}{l}\text { Possibilita a identificação clara da atividade desempenhada pela } \\
\text { empresa, em termos diretos e físicos. }\end{array}$ & 190 \\
\hline Abstrata & $\begin{array}{l}\text { Faz menção à atividade desempenhada pela empresa em termos } \\
\text { metafóricos e abstratos. }\end{array}$ & 107 \\
\hline Descritiva & Descreve de forma sintética as diversas áreas de atuação da empresa. & 105 \\
\hline Aspiracional & $\begin{array}{l}\text { Sinaliza quais são os desejos da empresa em termos metafóricos } \\
\text { e abstratos. }\end{array}$ & 192 \\
\hline Externa & Demonstra foco no ambiente (sociedade, clientes etc.). & 175 \\
\hline Interna & Demonstra foco interno (aspectos da própria empresa). & 122 \\
\hline Defensiva & $\begin{array}{l}\text { Revela postura conservadora ou defensiva em termos de } \\
\text { posicionamento de mercado. }\end{array}$ & 242 \\
\hline Agressiva & $\begin{array}{l}\text { Revela postura expansiva ou agressiva em termos de posicionamento } \\
\text { de mercado. }\end{array}$ & 55
\end{tabular}

*As ocorrências são mostradas em números absolutos. A cada par se soma o total do corpus (297).

Fonte: Elaborada pelos autores. 
Tendo em vista a metodologia proposta e o caráter intersubjetivo do processo classificatório, o Quadro 1 traz exemplos das classificações feitas pelos pesquisadores.

\section{Quadro 1}

\section{Classificações - exemplos}

\begin{tabular}{|c|c|}
\hline Categoria & Marcador semântico \\
\hline Concreta & $\begin{array}{l}\text { Desenvolver, produzir e comercializar carros e serviços que as pessoas prefiram comprar e tenham } \\
\text { orgulho de possuir, garantindo a criação de valor e a sustentabilidade do negócio. }\end{array}$ \\
\hline Concreta & $\begin{array}{l}\text { Atuar com excelência empresarial e responsabilidade socioambiental no setor de energia elétrica, } \\
\text { contribuindo para o desenvolvimento da sociedade. }\end{array}$ \\
\hline Concreta & Prestar serviços de saneamento, contribuindo para a melhoria da qualidade de vida e do meio ambiente. \\
\hline Abstrata & Conquistamos os clientes para sempre. \\
\hline Abstrata & Aproximar pessoas com segurança e inteligência. \\
\hline Abstrata & Nossa missão é promover o bem-estar. \\
\hline Descritiva & $\begin{array}{l}\text { Distribuir, industrializar e comercializar derivados de petróleo e seus correlatos com competitividade, } \\
\text { rentabilidade e responsabilidade social e ambiental. }\end{array}$ \\
\hline Descritiva & $\begin{array}{l}\text { Conectar pessoas, instituições e negócios por meio de soluções postais e logísticas acessíveis, } \\
\text { confiáveis e competitivas. }\end{array}$ \\
\hline Descritiva & $\begin{array}{l}\text { A ISA CTEEP tem como missão operar, manter e expandir sistemas de transmissão de energia elétrica } \\
\text { com excelência na prestação de serviços, baseada no desenvolvimento do capital humano e na } \\
\text { capacidade de inovação, para criar valor para nossos acionistas e demais stakeholders e contribuir } \\
\text { para o desenvolvimento sustentável do negócio. }\end{array}$ \\
\hline Aspiracional & Criar valores diferenciados. \\
\hline Aspiracional & Ajudar as pessoas a viver de forma mais saudável. \\
\hline Aspiracional & Ajudamos o mundo a produzir os alimentos de que precisa. \\
\hline Externa & $\begin{array}{l}\text { Fazer parte do dia a dia das pessoas nos postos de serviços, fortalecer a parceria com nossos } \\
\text { revendedores e valorizar as características de cada região em que estamos presentes. }\end{array}$ \\
\hline Externa & Alimentar o mundo e proteger o planeta de forma responsável. \\
\hline Externa & $\begin{array}{l}\text { Prover soluções energéticas sustentáveis, com excelência e competitividade, atuando de forma } \\
\text { integrada à comunidade. }\end{array}$ \\
\hline Interna & $\begin{array}{l}\text { Sermos os melhores naquilo que nos propusermos a fazer, com foco absoluto em nossas atividades, } \\
\text { garantindo os melhores produtos e serviços aos clientes, solidez aos fornecedores, rentabilidade aos } \\
\text { acionistas e a oportunidade de um futuro melhor para todos os colaboradores. }\end{array}$ \\
\hline Interna & Gerar renda aos cooperados com desenvolvimento sustentável do agronegócio. \\
\hline Interna & $\begin{array}{l}\text { A Copersucar tem como propósito gerar valor por meio da integração vertical da cadeia dos negócios } \\
\text { de açúcar e etanol. }\end{array}$ \\
\hline Defensiva & Prover energia e soluções para o desenvolvimento com sustentabilidade. \\
\hline Defensiva & Contribuir para o bem-estar da sociedade gerando e transmitindo energia \\
\hline Defensiva & $\begin{array}{l}\text { Acreditamos que a existência da nossa empresa deve ajudar a tornar o meio ambiente e a sociedade } \\
\text { melhores. }\end{array}$ \\
\hline Agressiva & Ser líder inquestionável no setor de aço. \\
\hline Agressiva & Conquistamos os clientes para sempre. \\
\hline Agressiva & Crescer ajudando nossos clientes a vencer. \\
\hline
\end{tabular}

Fonte: Elaborado pelos autores.

Dadas as categorias encontradas, os pesquisadores construíram, ainda, um modelo bidimensional combinando as perspectivas agressiva/defensiva e externo/interno, de modo a obter uma visão mais qualitativa do posicionamento das empresas. Essa combinação, portanto, resulta em quatro quadrantes, como segue: Cidadela (defensivo/interno); Embaixada (defensivo/ externo); Forte (agressivo/interno); Front (agressivo/externo), termos escolhidos pelos autores por seu potencial metafórico. 
A Figura 1 apresenta os resultados obtidos com essa combinação.

Figura 1

Modelo bidimensional

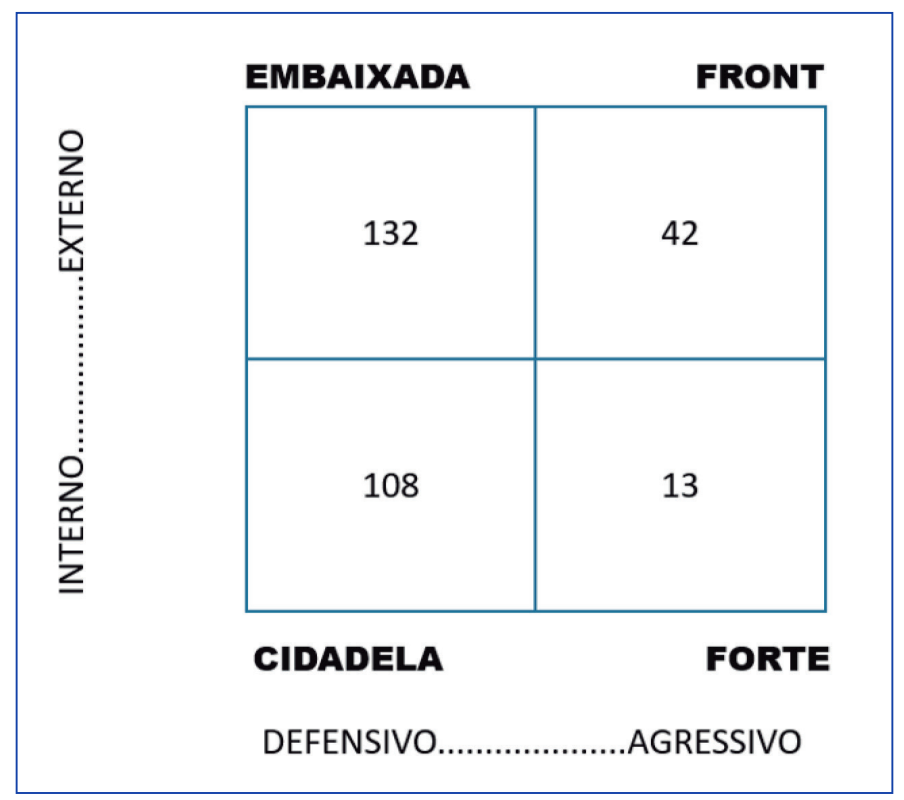

Fonte: Elaborada pelos autores.

\section{DISCUSSÃO}

Os resultados quantitativos são ambíguos. Trata-se de um percentual expressivo $(59,4 \%)$, porém, diante do fato de que a estratégia como design é tratada pela literatura há mais de 6 décadas e ter surgido, sobretudo na década de 1980, uma "febre" sobre DM, segundo Morphew e Hartley (2006), poder-se-ia esperar uma quantidade ainda maior. Ademais, o universo abrange as quinhentas maiores empresas nacionais, o que também gera uma expectativa de maior presença de DM.

Espera-se que as DM sejam mantidas simples e facilmente compreensíveis pelo corpo de colaboradores das empresas, razão pela qual se estipula que a quantidade de palavras em uma DM seja inversamente proporcional à sua qualidade (MINTZBERG, AHLSTRAND e LAMPEL, 2000). Na literatura internacional, os achados revelam DM variando em tamanho, conteúdo, formato e especificidade (PALMER e SHORT, 2008, KEMP e DWYER, 2003), embora no trabalho desses autores se encontre a recomendação de que as DM sejam informativas, inspiradoras, concisas, claras e capazes de gerar um elo emocional entre os colaboradores e a empresa. As recomendações de concisão, entretanto, na literatura internacional significam DM com até 100 palavras (M. E. DAVID, F. R. DAVID e F. R. DAVID, 2014). O valor encontrado, cerca de 25 palavras, é bastante inferior.

O fato da ampla maioria das DM serem iniciadas por verbo demonstra que, conforme previsto por Drucker (1973), as DM refletem um fazer específico, aquilo que distingue a empresa em relação às outras. A concisão se relaciona com a proposta teoria (DRUCKER, 2002) de que as DM eliminem a confusão entre colaboradores de uma empresa.

Quanto à compatibilidade entre as DM e o modelo descrito por Kotler (2000, p. 88), 71,7\% atendem aos 3 requisitos colocados. Esse grande percentual pode ser explicado pela forma como são construídas as DM. Trata-se de um processo reflexivo, seja interno, seja com a contribuição de consultorias externas, o que provavelmente faz com que os participantes busquem ou tenham contato com a literatura específica do assunto, gerando esse alto nível de conformidade.

Que algumas empresas explicitem suas metas e políticas/valores sem se preocupar com a explicitação dos escopos competitivos $(11,8 \%)$ pode relacionar-se tanto à tentativa de evitar a miopia do marketing como a uma ideia de que a empresa seja suficientemente reconhecida quanto à sua área de atuação para dispensar o escopo competitivo. A quantidade de empresas 
que explicitam metas e escopos competitivos, mas sem delinear suas/seus políticas/valores $(11,4 \%)$ pode estar relacionada ao fato de que correntemente se tornou usual que as companhias também tenham uma declaração de valores à parte, bem como uma declaração de visão, o que será objeto de desmembramentos desta pesquisa. Chama atenção a presença de uma DM que não permite a identificação de nenhum dos elementos: "gerar valor às pessoas". Quando combinada ao nome da empresa, essa DM pode até ser compreendida como a expressão de uma meta, contudo, tratada isoladamente, é por demais genérica, o que motivou sua classificação como ausentes as 3 dimensões.

Tendo em vista a metodologia proposta e o caráter intersubjetivo do processo classificatório, seguem-se alguns exemplos das decisões dos autores nesse quesito específico:

a) Presentes as três dimensões:

- Distribuir, industrializar e comercializar [METAS] derivados de petróleo e seus correlatos [ESCOPOS COMPETITIVOS] com competitividade, rentabilidade e responsabilidade social e ambiental [POLÍTICAS/VALORES].

- Atuar nos mercados de energia [METAS] [ESCOPO COMPETITIVO] de forma integrada, rentável e sustentável [POLÍTICAS/VALORES].

b) Presentes as dimensões "metas" e "políticas/valores":

- Ser uma empresa competitiva [METAS] inovadora e ousada que visa sempre ao bem-estar comum [POLÍTICAS/ VALORES].

- Conquistar os consumidores por meio de marcas e produtos diferenciados e de alto valor percebido, [METAS] criando valor para acionistas, empregados, fornecedores e clientes, e atuar com responsabilidades social $e$ ambiental [POLÍTICAS/VALORES].

c) Presentes as dimensões "metas" e "escopos competitivos":

- Ser líder inquestionável [METAS] no setor de aço [ESCOPO COMPETITIVO].

- Gerar valor com a integração de serviços para exploração e produção [META] no segmento de óleo e gás [ESCOPO COMPETITIVO].

d) Presente somente a dimensão "metas":

- Criar demanda e conquistar confiança todos os dias.

- Nossa missão é ajudar os clientes a eliminar as barreiras entre as ideias e os resultados.

A preferência por DM concretas pode ser relacionada ao objetivo de se ter uma DM - que é justamente clarear a razão de ser da empresa ou um fazer específico desta. DM ajudam na compreensão e facilitam a compreensão das áreas de atuação das empresas, porém, a preferência é por DM de cunho aspiracional. Esse resultado pode estar relacionado à previsão de Kotler (2000, p. 87): "as melhores declarações de missão são aquelas guiadas por uma visão, uma espécie de 'sonho impossível' que fornece à empresa direcionamento para os 10 a 20 anos seguintes". Aqui, pode haver certa sobreposição entre DM e declarações de visão, o que será objeto de desdobramentos desta pesquisa.

A preferência é por focar as DM no ambiente, o que corrobora com o fato de alguns dos termos mais frequentes encontrados se relacionarem ao externo: clientes, sustentável, desenvolvimento, valor, pessoas, soluções, vida, sociedade. M. E. David, F. R. David e F. R. David (2014) insistem na importância de que as DM tenham um foco externo, sobretudo na perspectiva do cliente, como forma de gerar impactos positivos na performance da empresa, por meio da melhoria dos índices de satisfação dos clientes.

Não obstante, um grande número (41\%) tem foco interno, o que pode ser relacionado à importância dada às competências essenciais e à teoria dos recursos. Já no tocante às dimensões defensiva/agressiva, a maioria das DM opta por evitar tons belicosos, adotando uma perspectiva de "cidadania corporativa" (defensiva, nos termos da pesquisa - 81\%). Esse resultado pode refletir uma prudência tanto institucional quanto jurídica, por parte das empresas, na linha de evitar provocar eventuais "adversários". Guimarães (2002, p. 93) afirma que "voluntária ou involuntariamente, as empresas emitem sinais, percebidos pelos competidores como indicadores dos próximos passos no jogo competitivo. Os sinais fornecem e transmitem informações essenciais em interações competitivas, por isso as empresas precisam saber emiti-los e decodificá-los com precisão". 
No tocante ao modelo bidimensional proposto, ressalte-se que não se trata de um ponto de chegada, mas de partida. Pesquisas futuras podem ser conduzidas para associar essas classificações a medidas de desempenho das empresas, conforme iniciativas similares de estudos internacionais (WILLIAMS, 2008; PEYREFITTE e DAVID, 2006; BART e BAETZ, 1998). Constata-se uma prevalência de DM com enfoque defensivo/externo (embaixadas) ou defensivo/interno (cidadelas). Poucas empresas optam, ao menos no nível discursivo, por posicionamentos agressivos. Esses resultados podem dizer respeito tanto a uma cidadania organizacional, inspirada por elementos do politicamente correto, quanto a estratégias deliberadas de sinalização para os competidores, como argumentado anteriormente, com base em Guimarães (2002).

\section{CONCLUSÃO}

A redação de DM é uma técnica da gestão estratégica, que tem por objetivo fornecer um senso de propósito compartilhado a todos os colaboradores das empresas. Amplamente difundida na década de 1980, tornou-se prática corrente no meio empresarial. A análise buscou verificar, tomando por universo as 500 maiores empresas brasileiras, o estado da arte desse assunto no Brasil.

Identificou-se que a ampla maioria das empresas apresenta uma DM em seus sites de internet, confirmando a ampla difusão da técnica, inclusive no Brasil. Contudo, talvez justamente por conta dessa elevada difusão, os resultados poderiam ser ainda maiores. Em termos de quantidade de palavras, as DM das empresas brasileiras apresentaram uma média inferior à média apontada pela literatura internacional. Predomina, nas DM, o foco externo, no cliente, o que é apontado como positivo pela literatura internacional.

No que tange à adequação técnica, considerando-se a proposta de Kotler (2000), verificou-se que a maioria das DM $(71,7 \%)$ atende ao modelo, em termos da presença dos 3 componentes apontados. As DM das empresas brasileiras conseguem sintetizar metas, políticas/valores e escopos competitivos em termos discursivos. Trata-se de um achado em língua portuguesa e em termos do contexto empresarial brasileiro. A partir dessa ampla base de empresas que apresentam uma DM adequada, reveladora da adesão das companhias nacionais às prescrições da literatura sobre gestão estratégica, abrem-se várias oportunidades de pesquisas adicionais, com o objetivo, por exemplo, de avaliar a assimilação efetiva das DM por parte dos funcionários, o impacto das DM sobre os resultados, a importância das DM para conformação das culturas organizacionais. Pode-se, também, aprofundar a dimensão da análise de discurso, com restrições amostrais, a exemplo do que fazem estudos internacionais.

O modelo bidimensional proposto pode contribuir para o caminho de pesquisa de comparação de resultados de desempenho das empresas tomando como referencial as classificações feitas. Ou seja, verificar se o posicionamento, ao menos no nível discursivo, como "embaixada", "cidadela", "front" ou "forte" produz diferenciais nos resultados financeiros das empresas.

Esta pesquisa supriu uma lacuna de estudos do gênero em língua portuguesa e aplicado à realidade empresarial brasileira, em que se pese a existência de uma diversidade de estudos na literatura internacional, muitos arrolados nas referências. Por se tratar de estudo inicial, adotou-se a perspectiva exploratória, que tem a vantagem de deixar o campo mapeado e aberto para uma série de outras pesquisas.

A principal contribuição teórica deste artigo é trazer a discussão para a língua portuguesa e para o contexto empresarial brasileiro. Haja vista a alta adesão das empresas às DM e o papel desempenhado por estas, o tema se mostra relevante e carece de desenvolvimentos, como argumentado. Em termos práticos, o estudo apresenta diversos elementos que propiciam que as empresas que já dispõem de uma DM reavaliem suas DM, buscando seu aperfeiçoamento e sintonia com as melhoras práticas, bem como disponibiliza vários apoios para aquelas empresas que se encontram em processo de formular suas DM. 


\section{REFERÊNCIAS}

ABRAHAMS, J. The mission statement book: 301 corporate mission statements from America's top companies. Berkeley, CA: Ten Speed Press, 1995.

AMATO, C. H.; AMATO, L. H. Corporate commitment to quality of life: evidence from company mission statements. Journal of Marketing Theory and Practice, v. 10, n. 4, p. 69-87, 2002.

ANSOFF, H. I.; MCDONNELL, E. J. Implantando a administração estratégica. São Paulo: Atlas, 1993.

BARDIN, L. Análise de conteúdo. São Paulo: Ed. 70, 2011.

BART, C. K. Mission matters. CPA Journal, v. 68, n. 8, p. 56-57, 1998.

BART, C. K. Lasting inspiration. CA Magazine, v. 133, n. 4, p. 49-51, 2000.

BART, C. K.; BAETZ, M. C. The relationship between mission statements and firm performance: an exploratory study. Journal of Management Studies, v. 35, n. 6, p. 823-853, 1998.

BART, C. K.; BONTIS, N.; TAGGAR, S. A model of the impact of mission statements on firm performance. Management Decision, v. 39, n. 1, p. 19-35, 2001.

BAUGHMAN, J. P. Problems and performance of the role of chief executive in the General Eletric Company. 1882-1974. Cambridge, MA: Harvard Harvard Graduate School of Business Administration, 1974. (Working paper).

BERGER, P. L.; LUCKMANN, T. A construção social da realidade: tratado de sociologia do conhecimento. Petrópolis, RJ: Vozes, 1985.

CAMPBELL, A.; YEUNG, S. Creating a sense of mission. Long Range Planning, v. 24, p. 17-23, 1991.

CHANDLER, A. D. Strategy and structure: chapters in the history of the industrial enterprise. Cambridge, MA: The MIT Press, 1962.

COELHO NETTO, J. T. Semiótica, informação e comunicação: diagrama da teoria do signo. São Paulo: Perspectiva, 2003.

COLLINS, J. C.; PORRAS, J. I. Organizational vision and visionary organizations. California Management Review, v. 34, n. 1, p. 30-52, 1991.

DAVID, F. R. How companies define their mission. Long Range Planning, v. 22, n. 1, p. 90-97, 1989.

DAVID, F. R. Strategic management: concepts and cases. Englewood Cliffs, NJ: Prentice Hall, 2007.

DAVID, M. E.; DAVID, F. R.; DAVID, F. R. Mission statement theory and practice: a content analysis and new direction. International Journal of Business, Marketing, and Decision Sciences, v. 7, n. 1, p. 95-110, 2014.

DAY, G. S.; REIBSTEIN, D. J. (Ed.). A dinâmica da estratégia competitiva. Rio de Janeiro: Campus, 1999.

DROHAN, W. Writing a mission statement. Association Management, v. 51, p. 117-132, 1999.

DRUCKER, P. F. Management tasks, responsibilities and practices. New York: Harper \& Row, 1973.
DRUCKER, P. F. O melhor de Peter Drucker: obra completa. São Paulo: Nobel, 2002.

EXAME. Melhores e maiores: as 1.000 maiores empresas do Brasil, Edição Especial, Editora Abril, São Paulo, SP, 11/08/2017.

FALSEY, T. A. Corporate philosophies and mission statements: a survey and guide for corporate communicators and management. Westport, CT: Greenwood, 1989.

GUIMARÃES, A. S. Estratégias competitivas adotadas por empresas de tecnologia de informação. Revista de Administração (São Paulo), v. 37, n. 3, p. 86-95, 2002.

IRELAND, R. D.; HITT, M. A. Mission statements: importance, challenge, and recommendations for development. Business Horizons, v. 35, n. 3, p. 34-42, 1992.

KEMP, S.; DWYER, L. Mission statements of international airlines: a content analysis. Tourism Management, v. 24, p. 635-653, 2003.

KING, W. R.; CLELAND, D. I. Strategic Planning and Policy. New York: Van Nostrand Reinhold, 1979.

KLEMM, M.; SANDERSON, S.; LUFFMAN, G. Mission statements: selling corporate values to employees. Long Range Planning, v. 24, n. 3, p. 73-78, 1991.

KOTLER, P. Administração de marketing: a edição do novo milênio. São Paulo: Prentice Hall, 2000.

KOTLER, P.; SINGH, R. Marketing warfare in the 1980's. Journal of Business Strategy, v. 1, n. 3, p. 30-41, 1981.

KRIPPENDORFF, K. Metodología de análisis de contenido. Teoría y práctica. Barcelona: Paidós, 1990.

LEVITT, T. Miopia do marketing. In: HARVARD BUSINESS REVIEW. Os essenciais: uma introdução aos conceitos mais relevantes da administração feita pela Harvard Business Review. São Paulo: Harvard Business Review, 2017. p. 148-171.

MINTZBERG, H.; AHLSTRAND, B.; LAMPEL, J. Safari de estratégia: um roteiro para a selva do planejamento estratégico. Porto Alegre: Bookman, 2000.

MORGAN, G. Imagens da organização. São Paulo: Atlas, 1996.

MORPHEW, C. C.; HARTLEY, M. Mission statements: a thematic analysis of rhetoric across institutional type. Journal of Higher Education, v. 77, n. 3, p. 456-471, 2006.

PALMER, T. B.; SHORT, J. C. Mission statements in U.S. colleges of business: an empirical examination of their content with linkages to configurations and performance. Academy of Management Learning \& Education, v. 7, p. 454-470, 2008.

PEARCE, J. A. The company mission as a strategic tool. Sloan Management Review, v. 23, n. 3, p. 15-24, 1982.

PEARCE, J. A.; DAVID, F. R. Corporate mission statements: the bottom line. Academy of Management Executive, v. 1, p. 109-114, 1987.

PEYREFITTE, J.; DAVID, F. R. A contente analysis of mission statements of United States firms in four industries. International Journal of Management, v. 23, n. 2, p. 296-301, 2006. 
PORTER, M. E. Estratégia competitiva. Rio de Janeiro: Campus, 1986.

PORTER, M. E. Vantagem competitiva. Rio de Janeiro: Campus, 1989.

PORTER, M. E. Competição: estratégias competitivas essenciais. Rio de Janeiro: Campus, 1999.

POWERS, E. L. Organizational mission statement guidelines revisited. International Journal of Management \& Information Systems, v. 16, p. 281-290, 2012.

SASHITTAL, H.; TANKERSLEY, C. The strategic market planningimplementation interface in small and midsized industrial firms: an exploratory study. Journal of Marketing Theory and Practice, v. 5, p. 77-92, 1997.
SELZNICK, P. Leadership in administration: a sociological interpretation. Evanston, IL: Row Peterson, 1957.

WILLIAMS, L. S. The mission statement: a corporate reporting tool with a past, present and future. Journal of Business Communication, v. 45, n. 2 , p. 94-119, 2008.

ZACCARELLI, S. B. Estratégia e sucesso nas empresas. São Paulo: Saraiva, 2000.

ZACCARELLI, S. B.; FISCHMANN, A. A. Estratégias genéricas: classificações e usos. Revista de Administração de Empresas, v. 34, n. 4, p. 13-22, 1994.

André Rehbein Sathler

ORCID: https://orcid.org/0000-0003-1856-9839

Doutor em Filosofia pela Universidade Federal de São Carlos (UFSCar); Professor titular na Escola de Negócios do Centro Universitário IESB, Brasília

-DF, Brasil. E-mail: andre.sathler@gmail.com 